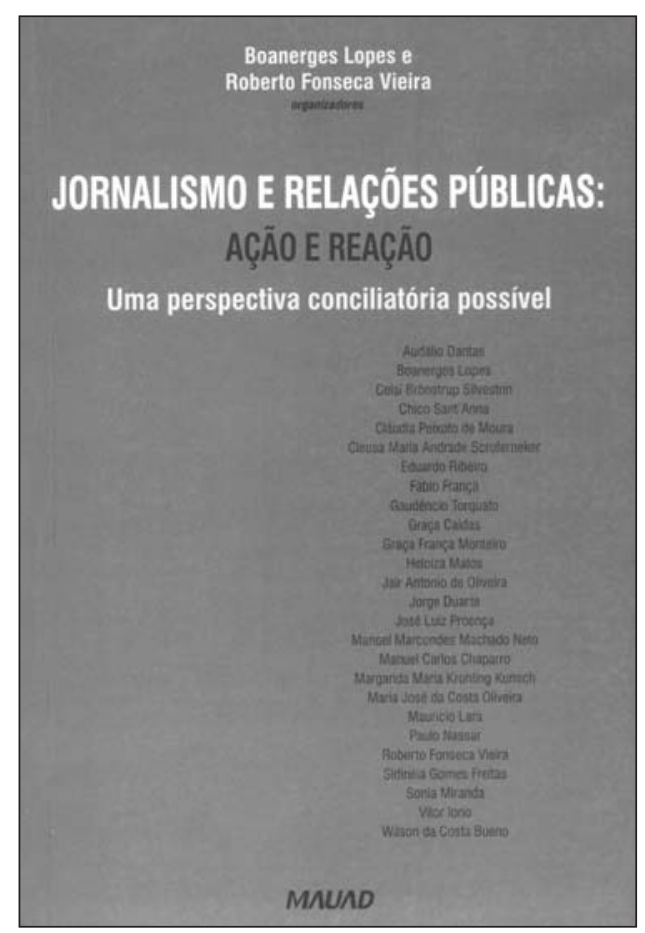

Boanerges Lopes e Roberto Fonseca Vieira (orgs.)

Jornalismo e Relações Públicas: ação e reação - uma perspectiva conciliatória possível

Rio de Janeiro, Mauad, 2004, 199 páginas

Mariângela Haswani

- Mestre em Ciências da Comunicação (Jornalismo Comparado) pela ECA-USP

- Bacharel em Jornalismo pela Faculdade Casper Líbero

- Professora do Departamento de Relações Públicas, Propaganda e Turismo da ECA-USP

- Consultora e pesquisadora com atuação em campanhas eleitorais e em órgãos públicos

- haswani@sti.com.br 


\section{Jornalistas e relações-públicas: as possibilidades e impossibilidades da conciliação}

$\mathrm{N}$ os anos de 1970, nos meios acadêmico e profissional, uma tripla rotulagem marcava a área da comunicação: publicitário era o criador supremo, acima das questiúnculas do mundo inferior; jornalista era aquele sujeito que tudo sabia, tudo conhecia - onisciente mesmo - e tinha nas mãos as rédeas da opinião pública; o relações-públicas era o contador de empadinhas.

Naquele tempo, comunicação empresarial resumia-se à publicação do "jornalzinho interno" - o diminutivo era depreciativo, não carinhoso - aliada, eventualmente, a "festinhas" comemorativas para funcionários, a cargo do departamento de Recursos Humanos. A sociedade amargava as restrições impostas pela ditadura militar às artes, à pesquisa e aos meios de comunicação.

Nessa conjuntura, os artistas uniram-se em frentes de reação e os intelectuais seguiram seus estudos no exílio. Jornalistas e relações-públicas permaneceram em seus postos, uns poucos abrindo novas frentes de atuação em territórios ainda incipientes e a maioria alimentando uma rotina de preconceitos e disputas, notadamente nas atividades de assessoria de imprensa, reivindicadas pelas duas categorias.

Hoje, a Comunicação Organizacional no Brasil ostenta o status de área estratégica na política, na economia, nos negócios, nas relações sociais. O país amadurece a vida em democracia e prepara suas armas para a sobrevivência e o crescimento no mundo globalizado. Uma evolução extraordinária.

Em Jornalismo e Relações Públicas: ação e reação - uma perspectiva conciliatória possivivel, Boanerges Lopes e Roberto Fonseca Vieira retomam, através dos autores convidados, a velha rusga entre profissionais da Comunicação, a partir de pontos de vista diversos, atuais e capazes de flagrar que a discussão do embate permanece nos anos de 1970.

Apresentada por três ícones da Comunicação - Manuel Carlos Chaparro, Margarida Maria Krohling Kunsch e Audálio Dantas - e prefaciado pelo pioneiríssimo Gaudêncio Torquato, a obra costura os fragmentos apresentados na abertura: o jornalista, o relações-públicas, as organizações, os meios de comunicação e o futuro.

As profissões de jornalista e de relações-públicas, suas inserções na Comunicação Organizacional e as origens históricas da disputa de espaço nas assessorias de imprensa 
compõem a parte em que a defesa da atividade de Relações Públicas aparece claramente, nos artigos de Sidinéia Gomes Freitas, Paulo Nassar e na introdução dos organizadores, Boanerges Lopes e Roberto Fonseca Vieira, sempre lastreados por pesquisas e estudos de caso, acadêmicos ou não, sob a ótica da instituição como emissor no processo da comunicação.

Outra vertente mostra duas profissões distintas, mas misturadas, confundidas em suas funções pela anarquia que a história da comunicação e das redações jornalísticas criou. Jair Antonio de Oliveira fala da conciliação (im)possível e propõe a tolerância tácita da "Hipótese de Poliana", um apelo à paz. Já Wilson Bueno não só admite o confronto jornalista/ relações-públicas como o considera um fator positivo, capaz de sacudir a cordata e acomodada comunicação empresarial, tão propensa "à obediência, sem questionamentos, à hierarquia, à assepsia nos sentimentos e relações”.

Sem dúvida, o momento mais crítico da obra acontece quando os autores lançam seus refletores sobre os jornais e o tratamento por eles dispensado à informação, principalmente aquela gerada e emitida pelas assessorias de imprensa. Questionam o "jornalismo de prateleira" (José Luiz Proença), em que as matérias são encomendadas aos assessores e editadas nas redações sem qualquer apuração pelos repórteres; a patética "marketização da informação" que Chico Sant'Anna vislumbra para o futuro e leva Manoel Marcondes Machado Neto a afirmar que "a crise é no jornalismo e não na comunicação".

Mas são as idéias de multidisciplinaridade e parceria na concepção e na ação das assessorias de comunicação que predominam na obra. O conceito de "bater laje", que Maurício Lara extrai dos mutirões, onde pessoas de origens e profissões distintas se reúnem para construir uma casa sem questionar de quem é esta ou aquela função, converge para as propostas de comunicação integrada do ponto de vista das organizações e, simultaneamente, para a informação conseqüente e responsável socialmente a ser produzida, reproduzida e veiculada pelos meios. Inserida na velocidade da tecnologia que transforma o panorama da Comunicação Organizacional, a parceria desponta como solução futura para uma disputa historicamente enraizada.

Alguns descuidos na revisão não chegam a comprometer seriamente a qualidade do conjunto, formado por textos agradáveis de se ler. Mesmo com elegância e inegável sutileza, as alfinetadas entre jornalistas e relações-públicas estão presentes, quer tratando da pasteurização dos noticiários, quer discutindo quais interesses são mais relevantes. Para Fábio França, o que interessa "não é discutir de quem é a mídia, mas sim apurar quem a conhece e sabe utilizá-la com competência e de maneira eficaz". Eu completaria: "e para o interesse público". 


\section{Outras publicações de referência}

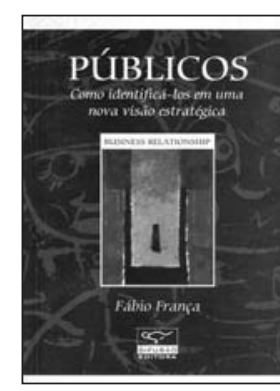

Públicos - como identificá-los em uma nova visão estratégica

Fábio França

São Caetano do Sul, SP:

Yendis Editora, 2004 159 páginas

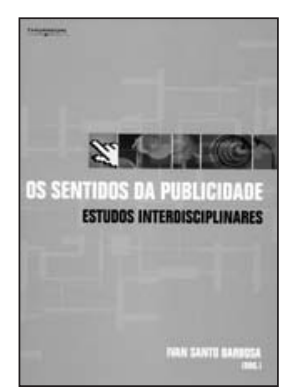

Os sentidos da Publicidade - Estudos interdisciplinares

Ivan Santo Barbosa

(Org.)

São Paulo: Pioneira Thomson Learning, 2005

180 páginas

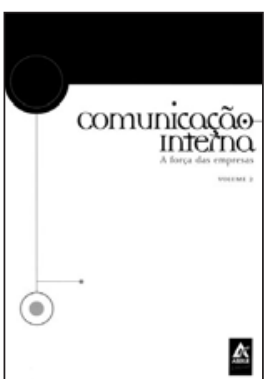

Comunicação Interna a força das empresas volume 2

Paulo Nassar (Org.)

São Paulo:

Aberje, 2005

175 páginas

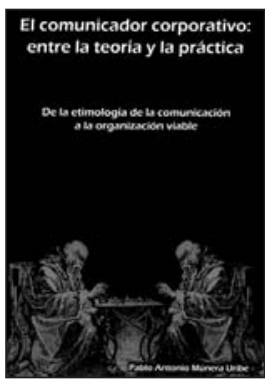

El comunicador corporativo: entre la teoria y la práctica De la etimologia de la Comunicación a la organización viable

Pablo Antonio Múnera Uribe

Medellín, Colômbia: Pablo Antonio Múnera Uribe, 2005 160 páginas

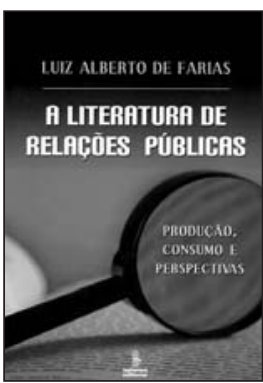

A literatura de Relações Públicas produção, consumo e perspectivas

Luiz Alberto de Farias

São Paulo:

Summus, 2004

166 páginas

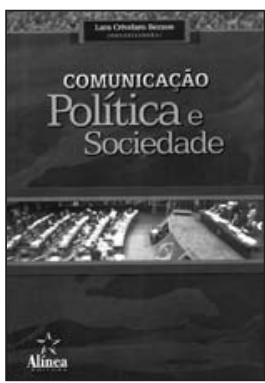

Comunicação, Política e Sociedade Lara Andréa Crivelaro Bezzon (Org.)

Campinas, SP: Editora Alínea, 2005 270 páginas 